\section{Research Square}

Preprints are preliminary reports that have not undergone peer review.

They should not be considered conclusive, used to inform clinical practice, or referenced by the media as validated information.

\title{
Impacts and Lessons Learnt From Local Production of WHO- Recommended Alcohol Based Hand Rub During Covid-19 Pandemic in Uganda
}

Tusabe Fred ( $\nabla$ tusabef@gmail.com )

Mbarara University of Science and Technology Faculty of Medicine https://orcid.org/0000-0002-9716-6917

\section{Morgan Otita}

Infectious Diseases Institute

Maureen Kesande

Infectious Diseases Institute

Twinomugisha Fred

Infectious Diseases Institute

\section{Research}

Keywords: COVID-19, Hand sanitizer, Hand hygiene, Infectious diseases, Uganda

Posted Date: April 30th, 2020

DOI: https://doi.org/10.21203/rs.3.rs-24752/v1

License: @ (1) This work is licensed under a Creative Commons Attribution 4.0 International License. Read Full License 


\section{Abstract}

The Government of Uganda through the Ministry of Health and other partners have promoted hand washing and hand rubbing using ABHS as one of the key preventive measures against person-to-person spread of the Covid- 19 virus. The people of Uganda have greatly heeded to these messages and as a result, the demand for ABHS has increased because of high consumption rates.

Methods: A district multi modal design was established in 2019 in Kabarole and Kasese districts in Western Uganda Part of the strategy was to set up an ABHS production units. The prevailing COVID-19 outbreak has instigated set up at centrally located Kasangati HCIV. We analysed the demand and production of ABHS produced before and during the COVID-19 outbreak.

Objective: To establish the impacts and lessons from local Production of WHO-recommended alcohol based hand rub during Covid-19 Pandemic

Results: 2060 litres were produced in Fort Portal in March 2020 around the time Uganda registered her first case of COVID-19 compared to monthly average production of 141 litres before the outbreak. In Kasese around 3020 litres were produced compared to the average 1500 litres while 2000 litres produced in Kasangati HCIV a newly set production unit and a total of 8 people trained on Local production of ABHS.

Conclusion; With high demand for ABHS during this pandemic, prices for commercial hand sanitizers have escalated, therefore, there is need to roll out local production of ABHS in other parts of the country since its saves more than $45 \%$ of the costs compared to commercial Hand Sanitizer. The production units should be embedded in Regional Referral Hospitals or IPC guidelines to major health facilities for the benefit of healthcare workers and patients who are at risk of the pandemic.

\section{Introduction}

A novel coronavirus (COVID-19) first detected in Wuhan City, Hubei Province in China on the 17th November 2019 has now spread globally. On the 30th January 2020, the WHO declared COVID-19 a Public Health Emergency of International Concern and later declared it a Global Pandemic on the 11th of March 2020(1)

Globally, there are currently over 2.4 million confirmed cases and 150,000 people have so far died. Uganda confirmed her first case on 21 st March 2020, a 36-year-old Ugandan male who arrived from Dubai presenting with symptoms of high fever and poor appetite. Uganda currently has 56 confirmed cases, 22 recoveries and no deaths have .been registered at the time of this paper(2).

Various public health measures have been put in place to prevent spread of COVID-19 including hand washing with soap and water, a recommendation that has been adopted in most countries. However, in the absence of soap and water, the World Health Organisation (WHO) and the Centres for Disease Control and Prevention (CDC) recommend using an alcohol-based hand sanitizer (ABHS) that contains at least 60 percent alcohol (also referred to as ethanol or ethyl alcohol) to combat the spread of COVID-19(3).

The World Health Organization (WHO) published 2 alcohol-based formulations to be used in healthcare settings and for outbreakassociated infections, inactivation efficacies of these products have been determined against (re-)emerging viruses(4)

Various studies have been done to demonstrate the efficacy of WHO-Formulations and the roles on reducing Hospital acquired infection(5) Another study demonstrates that SARS-CoV-2 was highly susceptible to the WHO formulations with reduction Factors greater than 5.9(6).

Multimodal hand hygiene campaign was piloted and established in two districts of western Uganda, this study therefore establishes the impacts and lessons learnt from local Production of WHO-recommended alcohol based hand rub during Covid-19 Pandemic.

\section{Method}

A district multi modal design was established in 2019 in Kabarole, a district in Western Uganda that was threatened by several outbreaks including Ebola. Part of the strategy was to set up an ABHS production unit. Production, distribution and consumption of ABHS were being monitored throughout 2019 to-date.

Another production unit was set up in neighbouring Kasese district in the same year 2019 during the Ebola outbreak in which 4 cases were imported in that district, monitoring majorly involved ABHS consumption monitoring that was carried out by Health centre IPC focal person and production quantities monitored by ABHS production personnel. The prevailing COVID-19 outbreak has instigated set up at centrally 
located Kasangati HCIV. We analysed the demand and production of ABHS produced before and during the COVID-19 outbreak, the factor was to look at demand and with an aim to study the variations if any in quantities of production.

\section{Implementing Of Abhs Production Units}

A multidisciplinary team from the Infectious Diseases Institute visited the suggested production sites by District officials. The rooms were well ventilated away from any kind of fire source with possibility of Lock and Key.

Facilities that had No Pharmacists, laboratory Technologists/Technicians were considered to be trained for ABHS production.

A cost evaluation analysis was made and found $45 \%$ savings on local production of ABHS especially in this time of the pandemic where costs of raw materials escalated due to demand by commercial manufactures.

\section{Abhs Distribution}

Distribution was integrated in the district drug distribution mechanism however during the pandemic consumption was higher that before and this prompted facilities to pick the ABHS from production Units using Facility motorcycles or vehicles.

Initial distribution was done by the Infectious diseases team that even taught health workers on how to use the ABHS where the WHO's " 5 Moments of Hand Hygiene" and "How to Hand Rub Technique" were distributed and used as the training materials for hand hygiene(7)

\section{Results}

2060 litres were produced in Fort Portal in March 2020 around the time Uganda registered her first case of COVID-19 compared to monthly average production of 141 litres before the outbreak. In Kasese around 3020 litres were produced compared to the average1500litres while 2000 litres produced in Kasangati HCIV a newly set production unit and a total of 8 people trained on Local production of ABHS.

\section{Discussion: Impact And Lessons Learnt}

This study demonstrated a component in the WHO-multi modal of hand hygiene strategy in a resource limited setting especially in Low middle income countries of Local production of $\mathrm{ABHS}(7)$

WHO Formulation 1 was majorly considered in this project due to availability of Ethanol unlike Isopropyl alcohol which is not readily available on market nevertheless Ethanol is also cost friendly

There was high demand of Locally produced alcohol hand sanitizer and this served as marker of hand hygiene compliance using sanitizers, many studies have demonstrated high hand hygiene compliance using ABHS compared to soap and water when hand are not feasibly $\operatorname{soiled}(8)$

Another study demonstrated poor tolerability of the WHO-recommended formulation of hand sanitizer and identified as a barrier of hand hygiene(9) however in this study we demonstrate high demand of locally produced ABHS to combat the pandemic which is a key sign to compliance and acceptability.

A total of 8 staff have been trained on local production using WHO protocol on local production, the ABHS was quality controlled using an alcoholmeter $75 \pm 85 \%$ ethanol. Staff will own production

Even when prices of raw materials escalated, costs of locally produced ABHS were lower than the commercial sanitizers and this made savings of $45 \%$ compared to savings of $60 \%$ before the pandemic. Costs of dispenser bottles escalated by $100 \%$ price compared to before the pandemic, in local production bottles were recycled after being cleaned with chlorinated water and this increased savings.

\section{Conclusion}

With high demand for ABHS during this pandemic, prices for commercial hand sanitizers have escalated, therefore, there is need to roll out local production of ABHS in other parts of the country since its saves more than $45 \%$ of the costs compared to commercial Hand Sanitizer. The production units should be embedded in Regional Referral Hospitals or IPC guidelines to major health facilities for the benefit of healthcare workers and patients who are at risk of emerging and Re-emerging Infectious diseases. 
Article Summary

Strengths and Limitations of the study

The study was able to capture data about ABHS production even before covid-19 pandemic

In the study more ABHS producers were trained

The study did not involve human subjects to observe hand hygiene compliance with ABHS.

\section{Abbreviations}

ABHS; Alcohol based hand sanitizer, WHO; World health Organisation, IPC; infection Prevention and Control

\section{Declarations}

\section{Ethics approval and consent to participate:}

Not applicable

\section{Competing interests;}

All authors had no competing interests (financial or otherwise) relevant to this article

\section{Funding:}

No special funding was received for this study

\section{Consent for publication:}

All Authors have read and agreed to publish the findings

\section{Availability of data and material:}

Technical appendix, statistical appendix and dataset will be available upon formal request.

\section{Author contributions;}

TF data collection, data analysis and manuscript writing, MO; Manuscript reviewing, KM; Data collection and Manuscript Reviewing

\section{Acknowledgements;}

Acknowledge districts that welcome ABHS local Production in Uganda

\section{Author details;}

${ }^{1}$ Infectious Diseases Institute, Global Health Security Department

\section{References}

1. Covid-19. challenges to gis with big data | elsevier enhanced reader [Internet]. [cited 2020 Apr 18]. Available from: https://reader.elsevier.com/reader/sd/pii/S2666683920300092? 
token=25E1255D4D083D39BFB6D042945E11FB42324CEA962303BAD6C165365ADB5877473ECC8692DA2F7DA2F1B95E2E2F09D1.

2. Coronavirus (COVID-19). What you need to know and learn I UNICEF Uganda [Internet]. [cited 2020 Apr 18]. Available from: https://www.unicef.org/uganda/coronavirus-covid-19-what-you-need-know-and-learn.

3. Kampf G, Todt D, Pfaender S, Steinmann E. (2020). Persistence of coronaviruses on inanimate surfaces and their inactivation with biocidal agents. The Journal of Hospital Infection, 104(3), 246-51. PubMed. https://doi.org/10.1016/j.jhin.2020.01.022.

4. Siddharta A, Pfaender S, Vielle NJ, Dijkman R, Friesland M, Becker B, Yang J, Engelmann M, Todt D, Windisch MP, Brill FH, Steinmann J, Steinmann J, Becker S, Alves MP, Pietschmann T, Eickmann M, Thiel V, Steinmann E. Virucidal Activity of World Health OrganizationRecommended Formulations Against Enveloped Viruses, Including Zika, Ebola, and Emerging Coronaviruses. J Infect Dis. 2017;215(6):902-6. https://doi.org/10.1093/infdis/jix046.

5. Fred T, Sophia K, Alex S, Emmanuel B, Tom L, Lucas A. (2020). Comparison of Antibacterial Efficacy of Locally Produced Alcohol Based Hand Sanitizer and Commonly Available Commercial Hand Sanitizer Used in Healthcare Facilities in Uganda. Open Access Library Journal, 7(4), 1-13.doi.10.4236/oalib.1106221.

6. $10.1101 / 2020.03 .10 .986711$

Kratzel A, Todt D, V'kovski P, Steiner S, Gultom ML, Thao TTN, Ebert N, Holwerda M, Steinmann J, Niemeyer D, Dijkman R, Kampf G, Drosten C, Steinmann E, Thiel V, Pfaender S. (2020). Efficient inactivation of SARS-CoV-2 by WHO-recommended hand rub formulations and alcohols [Preprint]. Microbiology. https://doi.org/10.1101/2020.03.10.986711.

7. World Health Organization, editor. WHO Guidelines on Hand Hygiene in Health Care: First Global Patient Safety Challenge: Clean Care Is Safer Care. Geneva: World Health Organization, Patient Safety; 2009.

8. Budd A, Lukas S, Hogan U, Priscille K, Fann K, Hill P, Edouard N, et al. A Case Study and the Lessons Learned from In-House Alcohol Based Hand Sanitizer Production in a District Hospital in Rwanda. Journal of Service Science Management. 2016;09(02):150-59. https://doi.org/10.4236/jssm.2016.92019.

9. Schmitz K, Kempker RR, Tenna A, Stenehjem E, Abebe E, Tadesse L, Jirru EK, Blumberg HM. Effectiveness of a multimodal hand hygiene campaign and obstacles to success in Addis Ababa, Ethiopia. Antimicrobial Resistance Infection Control. 2014;3(1):8.

https://doi.org/10.1186/2047-2994-3-8.

\section{Appendices}

\section{i) ABHS FACTS LABEL}

ABHS Active ingredient[s]; Ethanol $80 \% \mathrm{v} /$

Purpose :Antiseptic

Use[s] Health care personnel hand rub to help reduce Viruses, Bacteria and spores that can potentially cause disease

Warnings; For external use only. Flammable. Keep away from heat or flame Do not use on open skin wounds

When using this product keep out of eyes, ears, and mouth.

In case of contact with eyes, rinse eyes thoroughly with water. Stop use and ask a doctor if irritation or rash occurs. These may be signs of a serious condition. Keep out of reach of children. If swallowed, get medical help or contact a Poison Control Center right away.

Directions; Place enough product on hands to cover all surfaces. Rub hands together until dry. • Supervise children less than 6 years of age when using this product to avoid swallowing.

Storage information - Store between 15-30C (59-86F) • Avoid freezing and excessive heat above 40C (104F)

Ingredients; 96\% Ethanol, Glycerol, Hydrogen Peroxide and aqua

\section{ii) WHO-Recommended Formulation}




\begin{tabular}{|ll|}
\hline FORMULATION 1 & FORMULATION2 \\
\hline Final concentrations: & Final concentrations: \\
• Ethanol $80 \%(\mathrm{v} / \mathrm{v})$, & $\cdot \quad$ Isopropyl alcohol $75 \%(\mathrm{v} / \mathrm{v})$, \\
- Glycerol $1.45 \%(\mathrm{v} / \mathrm{v})$, & $\cdot$ Glycerol $1.45 \%(\mathrm{v} / \mathrm{v})$, \\
- Hydrogen peroxide $0.125 \%(\mathrm{v} / \mathrm{v})$ & $\cdot$ Hydrogen peroxide $0.125 \%(\mathrm{v} / \mathrm{v})$ \\
\hline
\end{tabular}

